\title{
IMIGRAÇÃO E PRESENÇA PORTUGUESA EM BELÉM NO SÉCULO XIX: Entre deslocamentos e pertencimentos (Pará-Brasil)
}

\author{
PORTUGUESE IMMIGRATION IN NINETEENTH CENTURY BELÉM: \\ Displacements and identities (Pará-Brazil)
}

\author{
Cristina Donza Cancela* \\ Luiz Guimarães*
}

\begin{abstract}
RESUMO: O trabalho analisa a imigração portuguesa em Belém, capital do estado do Pará, ao longo do século XIX. Trata-se de um período marcado por diversos conflitos políticos e prosperidade econômica na economia da borracha. Analisamos o fluxo migratório, as redes e a sociabilidade pautada pela moradia, o trabalho e as associações. Observamos também a construção de práticas e representações em torno da figura do português, dos conflitos políticos e da noção de colônia portuguesa, discutindo as estratégias de construção do ideal de uniformidade entre os imigrantes, a despeito das tensões e assimetrias existentes entre eles.
\end{abstract}

PALAVRAS-CHAVE: Pará. Imigração Portuguesa. Identidades.

ABSTRACT: In this paper we analyze the Portuguese immigration to Belém (capital of the state of Pará, Brazil) throughout the 19th century. The 1800s in the Brazilian Amazon Region was marked by several political conflicts and the rise of an economic prosperity context derived from the rubber exportations. We also observe the construction of practices and representations on the figure of the Portuguese and the notion of Portuguese Colony, discussing the strategies around the uniformity identities, despite the tensions and asymmetries between the immigrants.

KEYWORDS: Pará. Portuguese Immigration. Identities.

É comum ouvirmos a expressão "a colônia portuguesa do Pará", muitas vezes usada pelos próprios imigrantes em jornais, álbuns e livros. ${ }^{5} \mathrm{~A}$ despeito da palavra colônia inferir um sentido de unidade e simetria a esses imigrantes, criando o que Benedict Anderson oportunamente chamou de comunidade imaginária (ANDERSON, 2008), os imigrantes portugueses que aportaram no Estado possuíam diferentes marcadores sociais de classe, naturalidade, gênero e idade.

O livro O Pará e a colônia portuguesa, de autoria do escritor e cônsul português no Pará, Manoel Fran Pacheco, foi encomendado pela Junta Federativa das Associações Portuguesas do Pará. Nele temos o apanhado das diversas associações existentes em Belém, criadas pelos imigrantes ao longo do século XIX (PACHECO, 1920, p. 19). Ao fazer

\footnotetext{
* Professora da Universidade Federal do Pará, Programa de Pós-Graduação em História Social da Amazônia, Doutora, Pesquisadora CNPQ.

* Pesquisador do Grupo de Pesquisa "População, Família, Migração e Gênero na Amazônia - RUMA", Universidade Federal do Pará, Programa de Pós-Graduação em História Social, Doutor.

${ }^{5}$ Encontramos o uso do termo colônia portuguesa em vários livros, jornais e matérias produzidos no período estudado e que se estendem para o século XX. Assim, temos as obras: O Pará e a colónia Portuguêsa,. Belém: typographia da Livraria Gillet, 1920; o Álbum da colônia Portuguesa no Brasil. Organizado por Teófilo Carinhas e publicado pela oficina "Gráficas do Número" de Carinhas \& Cia Ltda, 1921, onde consta uma parte dedicada à presença portuguesa no Pará. E os jornais: Lusitano, que depois recebe o título de A colônia (1923-1928); Jornal O Portugal, que se intitulava o "orgam da colônia lusa no Norte do Brazil" (1918).
} 
referência aos lusos residentes na cidade, a expressão "colônia portuguesa" aparece em vários momentos, como se observa já no título da obra, ou em expressões como "assembleia da colônia", "empreendimento da colônia" (PACHECO, 1920, p. 20). O próprio Fran Pacheco, ao comunicar a criação da referida Junta Federativa ao Ministério dos Negócios Exteriores de Portugal, afirmou que a criação daquela Associação "significa um grande passo para a concórdia da populosa colónia aqui estabelecida". ${ }^{6}$ O termo esteve bastante presente na narrativa dos diversos agentes que construíram a história da imigração lusa no Pará.

Ao compor narrativas a partir da ideia de colônia, os imigrantes mobilizavam uma imagem de si em contraponto aos Outros, os nativos. Estabeleciam um elo entre o presente vivido no Pará e o passado acionado pela memória de suas vilas portuguesas, ordenando uma distinção pela origem. Embora eles tivessem a experiência de viver há vários anos no Estado, muitas vezes se casando, tendo filhos, negócios e bens, a distinção pelo lugar de origem permanecia na memória e na construção identitária, onde o ser português era potencializado pela frequência em associações nacionais, viagens constantes a Portugal, leitura de jornais portugueses, comemoração de datas históricas. Eles se misturam mas, ao mesmo tempo, se distinguem, demarcando a diferença deles, neste caso, os paraenses. Desse modo, sentidos de pertença, coesão e identidade são criados, realçando unidades e fronteiras, estabelecendo o diálogo com a sociedade local e seu distanciamento, num jogo de porosidades, mais do que de impermeabilidade (CANCELA, 2016). No entanto, para isso, era necessário fomentar o processo de construção da identidade cultural, a interação e a coesão, que passava pela noção de colônia.

Essa narrativa não se encontra apenas no discurso dos imigrantes e suas instituições, ela circula entre diferentes sujeitos, podemos encontrá-la mesmo em meio à população local.

Assim, nas comemorações do que se chamou o IV Centenário da descoberta do caminho marítimo para as Índias, o Governador do Estado do Pará, José Paes de Carvalho, assinou decreto transformando a data do dia 19 de maio de 1898 em feriado local. O político argumentou, a favor do ato, em função "da íntima cordialidade que ligam o Brasil a Portugal" e resolveu feriar no dia em que "a colônia portuguêza aqui estabelecida comemora jubilosamente o centenário indiano" (PACHECO, 1920, p. 22).

Ainda na esteira dessa decisão, no dia do feriado recém-criado, por ordem do secretário do governo, as fachadas das repartições estaduais foram iluminadas, a Associação Comercial do Pará pediu a seus sócios que fechassem a praça do comércio de Belém, os navios ancorados no porto levantaram suas bandeiras, as ruas foram ornamentadas por caixeiros e operários portugueses, morteiros e foguetes acordaram a cidade, as casas dos moradores foram enfeitadas e os jornais paraenses transmitiram congratulação pelo evento às folhas portuguesas.

As ações acima evidenciam o movimento da cidade de Belém em torno de uma data que remetia à memória institucionalizada e oficial da história portuguesa (COELHO, 2005, p. 363). Uma memória que se pretendia coletiva e agregadora, revivida em um evento catalisador da identidade lusa, que acionava símbolos diacríticos: os "gloriosos heróis portugueses", o "empreendimento português da navegação e dos descobrimentos". Símbolos que circulavam na narrativa dos vários agentes: comerciantes abastados, muitos deles fundadores da Associação Comercial Paraense, instituições mutualistas, caixeiros e operários, mas também nas instituições públicas paraenses, nas casas dos moradores locais e na imprensa, que deu destaque ao evento em seus principais jornais, exaltando o Portugal dos descobrimentos e que "seguia a sua trajetória gloriosa pelo trabalho de seus filhos em muitos quadrantes do mundo", destacando a cordialidade entre as duas nações (COELHO, 2005, p. 364).

Práticas como essas forjavam lugares de memória, construindo sentidos de ligação entre o Pará e Portugal e, também, compondo a identidade dos imigrantes portugueses no

\footnotetext{
${ }^{6}$ Ministério dos Negócios Externos, Correspondência do Consulado Português no Pará, Caixa n. 04, processo
} n.113, série D.1920. Grifo nosso. 
Estado, que se reconheciam e eram reconhecidos enquanto grupo, construindo aquilo que o cônsul de Portugal no Pará, Fran Pacheco, denominou a "grei lusónia", a alma portuguesa (PACHECO, 1920). Essas efemérides acionavam a identidade cultural, alimentando o sentido de pertença em diálogo com a sociedade local, num jogo que ora buscava a criação de fronteira e de singularidade, ora de compartilhamento e solidariedade com a população do lugar.

Mas, essa relação e os jogos identitários de pertencimento nem sempre se pautavam em comemorações e relações laudatórias. Ao longo de todo o século XIX, diferentes situações no jogo político influenciaram diretamente não apenas a relação do Pará com Portugal, mas também a forma como os imigrantes lusos marcaram a sua identidade no Estado, muitas vezes tendo que omitir o seu lugar de pertença.

É o que podemos depreender a partir da experiência do vice-cônsul português do Pará, na primeira metade do século XIX, Francisco Gaudêncio da Costa, durante o período da cabanagem, uma revolta política ocorrida entre os anos de 1835 e 1849, de caráter popular e abertamente antilusitano. ${ }^{7}$

Durante sua permanência à frente do Consulado, Francisco Gaudêncio registrou de que forma as ideias de liberdade, que fermentaram naqueles anos agitados politicamente, eram contrárias aos "maçons e portugueses no Pará" e não tardariam a causar temor entre os negociantes e as populações portuguesas ali estabelecidas. Notícias que circulavam no escritório do agente consular davam conta do cenário de medo que se armava. Da distante Vila de Santarém, cidade do interior do Estado, chegavam informações que "uma porção de facciosos armados urgiram as autoridades daquela vila a fazê-los dali sair em transtorno total de seus arranjos de vida e unicamente pelo motivo de terem nascido em Portugal"8.

Nessa mesma linha de preocupação, em março de 1835, após os ataques ocorridos em janeiro, desta feita na capital, Belém, um grupo de portugueses residentes no Pará, capitaneados pelo boticário José Acúrcio Cavaleiro de Macedo, remeteu uma carta para Lisboa à Sua Majestade, por meio do referido vice-cônsul, Francisco Gaudêncio da Costa, onde reclamavam providências para conter o risco de assassinato.

$\mathrm{Na}$ carta, afirmavam que o Consulado de Portugal não tinha "a honra de hastear o Pavilhão Português", pois se o fizesse "só serviria a indicar um depósito de vítimas". E que o vice-cônsul português, que igualmente possuía a função consular da Rússia, para se "fazer respeitar, saía à rua ataviado com o fardamento russo". ${ }^{10}$

Foi neste cenário perturbador para os lusitanos estabelecidos em Belém que Francisco Gaudêncio, em meio à ameaça iminente de morte, levou a perceber que, ser "português", "brasileiro" ou mesmo "russo" passou a constituir um tênue jogo de estratégia diante daquela situação extrema de conflito nacionalista que foi a cabanagem (SABINA, 1997; ROWLAND, 2008, p. 15-36; TRUZZI, 2016). As fronteiras de origem precisaram ser invisibilizadas e protegidas para fugir da ação repressiva dos chamados cabanos, que viam nos portugueses a representação da Coroa, do poder régio, dos políticos e dos comerciantes que, por anos, mantinham o controle econômico e político da província paraense. Os portugueses como um todo, mesmo aqueles que não faziam parte das elites de poder e de renda, passaram a simbolizar e traduzir a figura do antigo colonizador, responsabilizado pela condição de pobreza, das dificuldades sociais e políticas que a população atravessava. Como lembra José Saccheta Mendes, o antilusitanismo vai estar

\footnotetext{
7 A cabanagem foi um dos mais importantes movimentos populares da região norte do Brasil de caráter antilusitano. Teve a participação de diversos grupos da sociedade paraense, reunindo negros, índios, populações mestiças, proprietários rurais, entre outros. Trazia consigo rivalidades que se vinham arrastando desde a época colonial, explodindo na invasão a Belém, no ano de 1835. Esse episódio, que se estendeu até os anos de 1840, repercutiu em vários setores da sociedade, sendo debelado pelas forças do governo após dizimar milhares de indivíduos em todo o território paraense. Sobre este tema, ver: RICCI, 2011.

8 Instituto Arquivo Nacionais/Torre do Tombo (Lisboa), Ministério dos Negócios Estrangeiros, cx. 306, m0019.

9 Instituto Arquivo Nacionais/Torre do Tombo (Lisboa), Ministério dos Negócios Estrangeiros, cx. 306, m0029m0030.va.

10 Instituto Arquivo Nacionais/Torre do Tombo (Lisboa), Ministério dos Negócios Estrangeiros, cx. 306, m0029m0030.va.
} 
presente em diferentes contextos políticos ao longo do século XIX. Do processo de Independência à Proclamação da República, circulou a ideia de dualidade de postura da comunidade lusa no Brasil, onde se acreditava que alguns portugueses estariam ao lado da antiga colônia e de suas instituições e outros seriam contrários às causas nacionais (MENDES, 2010, p. 166).

Para além das questões patrióticas, esse antilusitanismo também se alimentava da ascensão dos comerciantes portugueses, da sua inserção política e, ao mesmo tempo, já na segunda metade do século XIX, da desconfiança em relação aos imigrantes lusos pobres que chegavam em massa ao Estado, muitos deles juntando-se às manifestações de trabalhadores e sendo acusados de causar desordem e fomentar greves (FONTES, p. 210).

Ao longo do século XIX, fosse entre as tensões e o perigo de ser luso num momento de luta nacionalista, ou entre as comemorações em torno do descobrimento das Índias, havia uma intensa presença portuguesa no cotidiano da cidade, marcada por práticas e representações que positivavam a origem de forma comemorativa e laudatória, mas também precisavam negá-la ou mesmo omiti-la, de acordo com as circunstâncias sociais. As relações políticas e econômicas entre as duas nações, assim como as condições e os conflitos locais, potencializavam alianças, mas também tensões e animosidades entre portugueses e paraenses.

\section{Fluxo, perfil e moradia dos portugueses em Belém}

A presença e ocupação portuguesa no Estado do Pará ocorreu ao longo de todo o século XIX. Do ponto de vista político, a primeira metade daquela centúria é considerada de crise devido a diversos conflitos ocorridos, como a invasão francesa em território português, no ano de 1808, com a consequente ocupação de Caiena, em 1809; a independência do Brasil e a adesão tardia do Pará, em 1823; e, finalmente, a revolta da cabanagem, entre os anos de 1835 e 1840. Esses conflitos deram forma a um cenário de hostilidade e conflito no cotidiano de lusos e nacionais, além de constante crise econômica em função das incertezas políticas. ${ }^{11}$

Do ponto de vista da economia, o início do século XIX foi marcado pelo crescimento do comércio da capital. Nesse momento, o Pará e o Maranhão ocupavam o quarto lugar dentre as capitanias exportadoras brasileiras, entre os anos de 1804 e 1807. As trocas eram intensas entre homens de letra e comércio de várias localidades, bem como entre a população de livres pobres, libertos e escravos (RICCI, 2003. p.169-170).

O cacau extraído das matas constituía-se no principal item de exportação da capitania. Os produtos da lavoura e da pecuária também se mantiveram presentes, movimentando o mercado interno e o comércio nos rios e igarapés do interior do Estado para a capital. Além disso, os produtos silvestres, como castanha e guaraná, eram exportados em grande quantidade, para a Europa e a América do Norte.

Já a segunda metade do século XIX é caracterizada por ser um período de prosperidade econômica para a província, dada a liquidez produzida pela economia da borracha. Momento conhecido como a bélle-époque paraense, marcado pelo crescimento da renda interna da província, da urbanização, do intenso fluxo migratório, do incremento nos negócios e no comércio, onde a presença portuguesa era acentuada.

É nesse cenário distinto que devemos pensar o fluxo migratório ao longo do século XIX para o Pará. Antes de conhecermos os números dessa migração, é preciso ponderar sobre as especificidades das fontes que nos dão acesso a esse quadro migratório. Enquanto as migrações finesseculares são bastante documentadas, tanto na saída de Portugal como na entrada do Brasil, os registros de mobilidade ainda são escassamente conhecidos no que diz respeito aos primeiros decênios dos oitocentos.

Desse modo, para a primeira metade do século XIX trabalhamos com os registros de passaporte existentes na documentação do Arquivo Histórico Ultramarino, no período de

\footnotetext{
11 As rivalidades que se vinham arrastando desde a década anterior ganharam as ruas de Belém no ano de 1835, com o grito de guerra "morte aos maçons e aos portugueses". (RAIOL, 1970).
} 
1800 a $1833^{12}$. A esta documentação acrescentamos a análise dos registros de passaporte dos arquivos distritais, correspondentes aos anos de 1835 a 1850, quando os passaportes começaram a ser emitidos pelo governo civil de cada distrito. ${ }^{13}$ Para a segunda metade do século XIX, trabalhamos com os livros de registro das habilitações de portugueses no Consulado Português no Pará, entre os anos de 1858 e $1900 .{ }^{14}$ Os Registros de Passaporte do distrito do Porto $^{15}$ e de Braga ${ }^{16}$.

O conjunto dessas fontes nos permitiu chegar ao número de 1.339 indivíduos embarcando em direção à província paraense entre os anos de 1800 e 1850. Número bastante tímido se compararmos aos alcançados na segunda metade do século XIX, quando tivemos um total de 7.055 imigrantes portugueses advindos de diversas regiões de Portugal, que fizeram registro no Consulado Português do Pará, entre os anos de 1858 e 1900. Devemos lembrar que esses números, mesmo que expressivos, ainda são subestimados, pois só levam em conta os imigrantes matriculados junto ao consulado português (CANCELA; COSME, 2016). Recentemente, realizando o levantamento dos livros de passaporte apenas do distrito do Porto, alcançamos um contingente de 10.879 imigrantes vindos para o Pará entre os anos de 1850 e 1900, esse número foi de 2.499, no Distrito de Braga. Ou seja, tomando como referência apenas esses dois distritos, temos um total de 13.378 indivíduos migrando para o Pará na segunda metade do século XIX, portanto quase o dobro dos 7.055 portugueses de diversas regiões que fizeram registro no consulado. É bem verdade que estes distritos estão entre os que apresentaram maior contingente emigratório, não apenas para o Pará, mas também para o Brasil (SERRÃO, 1974; SCOTT, 2002). De todo modo, o importante é realçarmos a expressividade da imigração portuguesa para o Pará em relação não apenas ao restante do Brasil, mas também à primeira metade do século XIX.

Esse deslocamento significativo de lusos para terras paraenses também é destacado por autores portugueses. Ao analisar a migração para o Brasil, Joel Serrão aponta o Pará como um dos primeiros destinos dos imigrantes portugueses (SERRÃO, 1974, p. 163-171). Da mesma forma, ao estudar a migração de Fafe e do Porto para o Brasil, Miguel Monteiro destaca o Pará como o terceiro Estado em fluxo de migrantes (MONTEIRO, 2000, p. 110). Em sua obra sobre a emigração do Porto para o Brasil, Jorge Alves, trabalhando com os registros de passaporte daquele distrito, entre os anos de 1836 e 1899, observa que o Pará está em segundo lugar (14,9\%) no destino migratório, seguido de Manaus $(12,9 \%)$ e atrás apenas do Rio de Janeiro (55,1\%) (ALVES, 1994, p. 243). Trabalhando com a emigração portuguesa especificamente para o Estado do Pará, João Cosme pontua o expressivo deslocamento que ocorre entre os anos de 1886 e 1900, evidenciando o pico havido após o ano de 1895, ao que atribui à retomada das relações diplomáticas entre Portugal e Brasil, 12 Os passaportes eram exigidos no reino desde o século XVIII e foram mantidos pelo governo ao longo de todo
o século XIX e início do XX. O controle dos deslocamentos também era realizado pelos consulados portugueses
pelo menos desde o ano de 1853 . Ver CANCELA; COSME, 2016. Para este trabalho, foram analisados os
passaportes dos arquivos distritais de Viana do Castelo, Porto, Villa Real, Lisboa e Coimbra. Cf. GUIMARÃES,
2015 .
13 Os Distritos faziam parte da divisão administrativa portuguesa, possuindo um representante do governo com
funções de caráter administrativo, dentre elas, a emissão de passaportes. Um Distrito congregava diversos
Conselhos e, estes, por sua vez, as freguesias. Os Distritos foram instituídos pela Lei de 25 de abril de 1835. Cf.
CAETANO, 1935.p. 18.
14 As habilitações consulares constituem-se em livros de registros de súditos portugueses mantidos pelo
consulado de cada localidade, e foram criados como uma forma de controle destes nacionais. A manutenção
desses registros constituía-se em uma das obrigações do consulado, como se depreende das disposições do
regulamento consular, que afirma a necessidade de registrar os emigrados assim que chegassem em seus
portos de destino. Ministério dos Negócios Estrangeiros. Documentos apresentados às Cortes. Regulamento
Consular Português. Decreto de 20 de março de 1855 . p. 259 .
15 Livro de registro de passaporte do Arquivo Distrital do Porto. Disponível em: $<$ http://pesquisa.adporto.arquivos.pt/viewer?id=411859>.

16 Livros de Registro de Passaporte do Arquivo Distrital de Braga. 
rompidas após a Proclamação da República, que foi seguida das tensões e críticas contra os portugueses acusados de defenderem a Monarquia. ${ }^{17}$

Essa migração das mais diversas regiões portuguesas gerou uma presença intensa de lusos circulando na capital paraense. Para termos uma ideia, de acordo com o censo de 1872 , cerca de $12 \%$ da população de Belém era formada por estrangeiros, destes, em torno de $80 \%$ eram portugueses. ${ }^{18}$

A maior parte desses imigrantes era originária das províncias do Douro e do Minho, seguidos das províncias da Beira Alta, Estremadura, Trás os Montes e Beira Baixa. É importante destacar que, em diversos casos, alguns desses imigrantes realizavam um deslocamento em etapas, como analisa Cosme em seu trabalho sobre a emigração portuguesa para o Pará, observando que boa parte daqueles que migraram já haviam saído de suas freguesias para a capital, Lisboa, ou mesmo o Porto, e, apenas depois de algum tempo naquelas cidades, faziam a travessia oceânica, caracterizando uma mobilidade interna em Portugal antes da decisão de migrar para o Pará (COSME, 2015, p. 84).

Esses imigrantes eram em sua maioria homens e chegavam majoritariamente na idade entre 20 e 35 anos, atuando em atividades associadas ao comércio, na condição de proprietário, caixeiro ou empregado comercial. Quando levantamos os passaportes do Distrito do Porto, além das atividades voltadas ao comércio, destacam-se também os ofícios de alfaiate, carpinteiro, pedreiro, ourives, padeiro, tanoeiro, marinheiro e trabalhadores da lavoura. ${ }^{19}$ Entre as mulheres, as atividades associadas aos serviços domésticos predominaram, com destaque para as engomadeiras e lavadeiras. ${ }^{20}$

O deslocamento português para o Pará ao longo de todo o século XIX possui diversos fatores. Visto como terra de esperança e de fortuna, o Brasil também serviu de espaço de asilo para indivíduos que foram forçados a deixar sua terra por conflitos políticos, como foi o caso da guerra civil (1828-1834), no tempo de D. Miguel. Exemplo dessa influência da situação política portuguesa para a imigração lusa, na primeira metade do século XIX, pode ser vista a partir da trajetória do já referido Francisco Gaudêncio da Costa. Lusitano, natural do distrito do Porto, possuía negócios nesta cidade quando o jovem D. Miguel (1828-1834) assumiu o trono e iniciou um período que foi considerado como "de maior repressão política da história portuguesa" (PEDREIRA; MONTEIRO, 2013. p. 69) quando milhares de lusitanos ligados aos grupos liberais deixaram Portugal ou ficaram lá escondidos por anos.

Francisco Gaudêncio deixou a cidade do Porto em meio à usurpação do trono e se deslocou para Belém, cidade que não escolheu de forma aleatória. Na vizinha cidade de São Luís do Maranhão já se encontrava, desde $1821^{21}$, seu irmão João Gualberto da Costa, destacado negociante daquela Praça, desfrutando de posições privilegiadas na sociedade maranhense. ${ }^{22}$

\footnotetext{
17 João Cosme realiza sua análise a partir dos pedidos de passaporte depositados no Arquivo Nacional da Torre do tombo, Lisboa, entre os anos de 1886 e 1900. Cf. COSME, 2015.

18 Brazil Directoria Geral de Estatística. Recenseamento da população do Império do Brazil 1872, Rio de Janeiro: 1873-1876, Parte 10, (Microfilme HA971-A2), Instituto Brasileiro de Geografia e Estatística. Recenseamento de 1920. População do Brasil por Estados, Municípios e Districtos segundo o sexo, o estado civil e a nacionalidade. Tabela $\mathrm{V}$.

${ }^{19}$ Livros de Registro de Passaporte do Arquivo Distrital do Porto. Anos 1850-1900.

20 Livro de Registro das Habilitações Consulares, Biblioteca Grêmio Literário Português. Ano: 1850-1918. Livros de Registro de Passaporte do Arquivo Distrital de Braga 1868-1900. Livros de Registro de Passaporte do Arquivo Distrital do Porto. Anos 1850-1900.

21 Desde 1821 o nome de João Gualberto da Costa aparece entre os assinantes e subscritores do Jornal Conciliador do Maranhão, residentes na cidade de São Luís. Ainda no mesmo periódico, consta que estava entre os cidadãos lusos que compareceram na Casa da Câmara no dia 19 de dezembro de 1822, a fim de prestar juramento de fidelidade a El Rei Constitucional e à Constituição da Monarquia Portuguesa. Jornal O Conciliador do Maranhão, n. 151, Ano 1822, 21 de dezembro. <http://memoria.bn.br/DocReader/DocReader.aspx?bib=749524\&PagFis=86\&Pesq=jo\%C3\%A30\%20gualberto> Acesso em: 15 mar. 2016.

22 Jornal O Conciliador do Maranhão, n. 39, Ano 1821, 24 de novembro. <http://memoria.bn.br/DocReader/docreader.aspx?bib=749524\&pasta=ano\%20182\&pesq=jo\%C3\%A3o\%20gualb erto>. Acesso em: 15 mar. 2016.
} 
Esses contatos podem ter contribuído para que Francisco, com pouco tempo residindo em Belém, tivesse negócios de exportação entre os portos do Pará, Maranhão e Lisboa e, depois, fosse nomeado vice-cônsul de Portugal na província paraense, como já visto.

Foi durante o exercício da atividade consular, através das correspondências que enviava para Lisboa, que ficamos sabendo como Francisco saiu de Portugal em 1829 e, ainda, que ele pretendia retornar para sua cidade natal, pois a função consular causava-lhe incômodo. Em 6 de setembro de 1834, após ter notícias da restauração do trono em nome de D. Maria II, Francisco Gaudêncio da Costa remeteu uma carta para o Ministério dos Negócios Estrangeiros dirigida ao senhor Agostinho José Freire. Nesta missiva, recordava que "eu tendo emigrado de Portugal no ano de 1829, quando teve lugar da usurpação da Monarquia", e, de acordo com as boas novas da restauração, manifestava o desejo "de ahi regressar, ao mesmo Augusto Senhor": "pesso a minha demissão, a qual tendo já requisitado ao Cônsul Geral do Rio de Janeiro, não a ma quis dar sem a ordem superior". ${ }^{23}$

Francisco, entretanto, não conseguiu a sua "demissão" do cargo do vice-consulado da nação portuguesa no Pará como requeria. Permaneceu no Pará até outubro de 1835, quando, junto com outros súditos portugueses, foi obrigado a fugir, novamente por questões de conflito político, a cabanagem, desta feita saindo do Pará para Portugal a bordo da Corveta "Elisa". 24

Se a colonização e os conflitos políticos têm uma força importante no deslocamento de indivíduos na primeira metade do século XIX, a economia da borracha, no Pará, somada à crise na lavoura, na pesca e no artesanato, em Portugal, são os grandes propulsores desse movimento populacional na segunda metade do século XIX.

Não podemos esquecer que esse é o período da migração portuguesa moderna, que tem o Brasil como principal destino (PEREIRA, 2002. p. 15-24). É também o fim do tráfico de africanos ocorrido após 1850, que abriu a necessidade de mão de obra e o incentivo para que um número expressivo de portugueses migrasse. É nesse cenário que Belém vai se tornar um dos principais destinos dos imigrantes lusos, atraídos pela possibilidade de ascensão social em função dos negócios movimentados direta, ou indiretamente, pela goma elástica. Some-se a isto o fato de a cidade implementar e ampliar seus equipamentos e serviços urbanos em função da liquidez, e, ainda, o início da navegação a vapor, facilitando e aumentando os deslocamentos ao reduzir o tempo de viagem. ${ }^{25}$

A presença de portugueses nas ruas da capital paraense, por onde chegavam os imigrantes dos portos portugueses, se torna comum. Do comerciante ao artesão, do pedreiro ao lavrador, das criadas às lavadeiras e amas de leite, esses imigrantes vão oferecer seus serviços e jornadas. Em carta ao Ministério dos Negócios Exteriores, o cônsul português no Pará destacava: "Os serviços de frete, carretos, recados, limpeza das casas etc. que em Lisboa, por exemplo, são feitos por galegos, são aqui exclusivamente desempenhados por compatriotas nossos. O moço da esquina no Pará é portuguez". ${ }^{26}$

$E$, assim, seguiam os portugueses não abastados, que chegavam a Belém na terceira classe dos navios, trabalhando de diária, realizando jornadas pouco valorizadas e parcamente remuneradas, exercendo funções e ofícios nem sempre semelhantes àqueles praticados em Portugal, como a de vendedores de leite, carregadores, condutores de bonds, seringueiros.

Uma vez em Belém, boa parte desses imigrantes vai residir nos quartos acima das lojas onde trabalhavam, nas casas de porta e janela, ou, mesmo, nas habitações coletivas como cortiços e vacarias.

\footnotetext{
23 Instituto Arquivo Nacionais/Torre do Tombo (Lisboa), Ministério dos Negócios Estrangeiros, cx. 306, m0020.

${ }^{24}$ Arquivo Histórico da Marinha de Portugal (Lisboa), Documentos Avulsos referentes à Corveta Elisa, 6-V-2-1.

$25 \mathrm{O}$ comércio da goma elástica se acentua regionalmente, particularmente a partir da década de 1850 , tendo alta no ano de 1860, firmando-se na pauta de exportação a partir de 1870. A partir daí, a economia da borracha se consolida ao longo de todo o século XIX e início do XX, entrando em crise a partir do ano de 1911, quando outros produtos ganham maior espaço na lista de exportação, como a castanha-do-Pará.

${ }^{26}$ Ministério dos Negócios Externos (Lisboa). Correspondência do Consulado Português no Pará. Série B doc.40 carta dirigida ao exmo. Ministro dos negócios.1912. Grifo original da fonte.
} 
Encontramos uma destas vacarias na rua das Flores, onde o proprietário e os leiteiros que lá habitavam eram de nacionalidade portuguesa e tinham idades que variavam entre 22 e 46 anos. Dentre eles, dois eram casados e os quatro restantes, solteiros, inclusive o dono do estabelecimento. ${ }^{27}$

Não eram incomuns situações em que os empregados de um estabelecimento comercial moravam no mesmo local em que trabalhavam. Geralmente, as firmas funcionavam em prédios assobradados, cujos altos possuíam quartos onde residiam os empregados, particularmente os solteiros. Nesta situação, viviam os caixeiros lusos Antônio de Mello e Antônio Saldanha, que habitavam nos altos do sobrado onde ficava o armazém no qual trabalhavam, juntamente com o patrão, o português Joaquim. ${ }^{28} \mathrm{O}$ mesmo ocorria com dois imigrantes portugueses, ambos com a alcunha de Manoel, empregados na "Pharmacia Chermont", à travessa 15ำ de Novembro, no comércio de Belém, que residiam nos altos do prédio. ${ }^{29}$

Ofertas desses espaços de moradia que funcionavam no local de trabalho podiam ser encontradas nos anúncios dos jornais da época, como a propaganda do ano de 1876, veiculada no periódico A Província do Pará, onde se anunciava o aluguel de "um sobrado por cima da loja Flora, bons commodos, próprio para pessoas empregadas no commércio. Ajusta-se na loja Flora". ${ }^{30}$ Como dissemos anteriormente, boa parte dos imigrantes portugueses atuava em atividades comerciais, o que nos permite pensar que moradias como a acima descrita no anúncio, "próprio para pessoas empregadas no comércio", fossem comumente ocupadas por portugueses.

As casas de porta e janela também serviam de moradia a esses imigrantes, muitas delas de propriedade de seus patrícios. O investimento na compra de casas e prédios para alugar era comum entre os portugueses mais abastados, que concentravam na atividade rentista boa parte de sua renda (TAVARES, 2015; CANCELA, 2011). Para citarmos um exemplo, destacamos os bens do português Antônio Maia, que, em 1877, possuía um total de 29 imóveis, sendo a maioria casa de porta e janela. Uma de suas casas fora alugada por outro luso, contra quem abriu queixa no ano de 1871 :

o queixoso alugou aos querellados um prédio de sua propriedade sito a rua da Trindade, canto com a rua dos Martyres, onde se achavam estabelecidos com casa de pasto, e no dia 24 do corrente sabe o queixoso que o querellado se havia mudado furtivamente sem the entregar as chaves da casa nem pago os aluguéis arrendando o fogão da cozinha e praticando danificação. ${ }^{31}$

A casa em questão era alugada para um comerciante português, de 31 anos de idade, chamado Joaquim da Silva. Ela fora avaliada seis anos depois, no inventário de Antônio Maia, em quatro contos de réis, caracterizada como sendo de má construção. ${ }^{32}$

Segundo o acusado e inquilino: "quando se mudaram para a referida casa, não tinha fogão..., e que o fogão que atualmente existe na casa foi mandado fazer a custa do accusado." O auto é julgado improcedente, pois as testemunhas arroladas confirmam a versão de que a chapa era de propriedade dos acusados e, com relação à danificação da

\footnotetext{
${ }^{27}$ Centro de Memória da Amazônia, (Belém-Brasil), Processos Crimes, ํㅡㄹistrito, Ferimentos graves, 1888, Doc 01 , Caixa:1888 (2).

${ }^{28}$ Centro de Memória da Amazônia, (Belém-Brasil), Processos Crimes, 2ํDistrito, Calúnia, 1877, Doc 01, Caixa 01 (1899).

${ }^{29}$ Centro de Memória da Amazônia, (Belém-Brasil), Processos Crimes, 3ํDistrito, Ferimentos leves, 1898, Doc 01, Caixa 01 (1898).

30 A loja Flora localizava-se no bairro comercial da Campina e constituía-se em um bazar que vendia artigos de perfumaria, moda, miudezas e bijouterias importadas. Jornal A Província do Pará, 7 abr. 1876, p. 3.

${ }^{31}$ Arquivo Público do Estado do Pará (Belém-Brasil), Auto crime, Fundo de Segurança Publica,1871.

32 Centro de memória da Amazônia (Belém-Brasil), Cartório Odon Rhoussard, Inventário Antônio da Silva Maia, Caixa, 1877. 1877.
} 
casa, o parecer afirmou que: "outros pequenos dannos são provenientes do uso regular que um inquilino faz da casa alugada, que não há crime em face da lei, como é sabido". ${ }^{3}$

Situações como essas dão visibilidade às diferenças de condição social e de trajetória dos imigrantes portugueses, evidenciando práticas de tensão e conflito que pulverizavam a imagem uniforme e simétrica da "colônia".

As tensões entre os portugueses residentes no Pará podem ser percebidas em diversos momentos. Destacamos anteriormente a carta que o boticário José Acúrcio Cavaleiro de Macedo, juntamente com um grupo de portugueses, enviou à Sua Majestade. $\mathrm{Na}$ carta, entre outros assuntos, o grupo reclamava do vice-cônsul português por não autorizar o pedido de auxílio com as despesas de regresso a Lisboa. Por sua vez, o vicecônsul se justificava, afirmando que isso ocorria devido ao fato de que "os vários indivíduos que assinam a carta não estavam regularmente habilitados neste consulado". ${ }^{34}$

A justificativa acima remete às orientações recebidas pelas representações consulares portuguesas para controlar e regularizar os lusitanos que entravam nos portos estrangeiros. Essas orientações aparecem, por exemplo, no Alvará de 13 de agosto de 1760, que instituía regras obrigatórias ao uso de passaporte para sair do reino, evitando a crescente imigração clandestina. ${ }^{35}$

Assim, para habilitar-se junto ao consulado, o imigrante deveria comprovar que não havia partido em desacordo com o que previa a legislação, ou seja, deveria ter seu passaporte emitido, comprovando com a posse desse documento, que não havia viajado clandestinamente. ${ }^{36}$ Por outro lado, estar registrado no consulado significava ter o direito de cidadão português legalmente reconhecido no estrangeiro, recebendo o amparo e as prerrogativas legais que o Estado luso deveria conceder aos seus súditos, entre elas, o levantamento de espólio de imigrantes falecidos no estrangeiro (na ausência de herdeiros legais), a não obrigatoriedade do serviço militar na nação de acolhimento e o recebimento de assistência em situações de dificuldade. ${ }^{37}$

A carta enviada pelo grupo de portugueses ao Ministério das Relações Exteriores de Lisboa trazia à tona não apenas o desassossego com os levantes cabanos, o atrito e as tensões dos súditos com o cônsul no Pará, mas, também, a fragilidade do consulado no registro e no controle institucional dos súditos, a despeito da legislação vigente.

Em resposta ao cônsul, os súditos portugueses remetentes da carta encabeçada pelo boticário José Acúrcio Cavaleiro de Macedo afirmavam não regularizar sua condição junto ao consulado, porque "são emigrados, que durante o reinado da usurpação, saíram da

\footnotetext{
${ }^{33}$ Arquivo Público do Estado do Pará (Belém-Brasil), Auto crime, Fundo de Segurança Publica, 1871.

34 Instituto Arquivo Nacionais/Torre do Tombo (Lisboa), Ministério dos Negócios Estrangeiros cx. 306, m0035. Sobre questões relativas às habilitações consulares, ver CANCELA; COSME, 2016.

${ }^{35}$ Este Alvará regulava a expedição de passaportes e seus emolumentos e, em seu item 1, recomendava o seguinte: "Todas as pessoas que quizerem sahir da Corte, e cidade de Lisboa, serão obrigadas a tirar passaportes, que lhes mandarão passar os Ministros de Bairros, em que morarem pelos seus respectivos escrivães" Cf: Alvará regulando a expedição de passaportes e seus emolumentos, de 13 de Agosto de 1760. Lisboa: reimpresso na Officina de Miguel Rodrigues, 1760. Disponível em: <http://purl.pt/22872>. Acesso em: 28 jan. 2019.

${ }^{36}$ Vale lembrar que, desde o Alvará de 13 de agosto de 1760, Portugal já regularizava a emissão de passaportes para indivíduos que desejavam transitar dentro e fora da Corte. Nesta Lei, o passaporte deveria descrever "com distinctos signaes as suas pessoas". Já no Edital de 19 de fevereiro de 1811, além dos sinais individuais físicos, passou-se a exigir, nos passaportes, dados referentes a: nome, filiação, naturalidade, estado, ocupação, lugar da morada, subscrição do portador quando sabia escrever; mas também nome, morada e ocupação do abonador. Outras exigências também se somavam a este controle de mobilidade, tais como: apresentar comprovante de serviço militar ou sua dispensa. Embora as leis de controle das mobilidades existissem desde o final do século XVIII, isto não impediu a migração clandestina, gerando um conjunto de tardios registros de habilitação no consulado da Província do Pará. Cf: Alvará regulando a expedição de passaportes e seus emolumentos, de 13 de Agosto de 1760. Op. cit.

${ }^{37}$ Correspondência do Cônsul ao Ministério dos Negócios Estrangeiros de 30 de julho de 1844. Instruções pelas quaes se devem Regular os Cônsules de Portugal nos Portos Marítimos dos Estados e Repúblicas por onde Navegão e Comerceão os vassalos portugueses e Tarifas dos Emolumentos que eles devem vencer nos Portos onde Residem, enquanto não se mandar o contrário. Código Comercial Portuguez, Lisboa: Imprensa Nacional, 1833. p. 226-227.
} 
Pátria, fugindo ao furor e aos cadafalsos". ${ }^{38}$ Nessas circunstâncias, não podiam ter procedido às devidas exigências legais de viagem.

É importante destacar que o vice-cônsul também havia migrado para o Pará fugindo das mesmas perseguições em Portugal. Contudo, naquela nova circunstância, representava os interesses do Estado luso no Estado e, em seu favor, alegava não possuir recursos suficientes para custear o transporte dos requerentes, posto que havia "pago muitas passagens e dado esmolas a muitos portugueses, de maneira que, sendo os emolumentos do vice-consulado coisa muito diminuta ${ }^{39 ",}$, não havia como efetivar o gasto, e, ainda, que "os indivíduos que contra ele fazem reclamações com "grande espalhafato e acusações [...], como contra a Sua Majestade Fidelíssima, são de pouco crédito". Assim, Francisco Gaudêncio da Costa reitera que o primeiro assinante da missiva, José Acúrcio Cavaleiro de Macedo, era "um homem de gênio turbulento, pelo que já havia sido deportado desta província em 1831". ${ }^{40}$ Acrescentava, ainda, sobre o boticário: "depois de ter voltado, por aqui tem andado com o 'lenço do Brasil', e o mesmo me disse ter se justificado brasileiro, circunstância que não posso afirmar, por não estar na cidade o escrivão, onde se disse ter prestado a dita justificação"41. Quanto aos demais solicitantes, alegava: "são alguns brasileiros adotivos e outros são pessoas pouco conhecidas, e de nenhuma ponderação". ${ }^{4}$

Esse debate nos remete mais uma vez às tensões internas existentes entre os portugueses e, ao mesmo tempo, nos ajuda a discutir a complexidade dos jogos identitários em que viviam esses imigrantes, como assinalado no início do trabalho. Enquanto o vicecônsul havia se "dissimulado", vestindo-se com o uniforme da Rússia, para poder sair às ruas da cidade ocupada pelos cabanos, o boticário, José Acúrcio Cavalero de Macedo, primeiro identifica-se como "brasileiro", por ter saído ilegalmente de Portugal, fugindo à guerra civil entre liberais e monarquistas, e, já alguns anos depois, reclamava ser "português", fugindo dos conflitos nacionalistas da cabanagem.

Destarte, numa cidade como Belém do Pará, em meio às crescentes hostilidades antilusitanas, ser "brasileiro" ou ser "português" representava mais do que o lugar de nascimento. Vinculava-se a um jogo de necessidades políticas que podia implicar na assimilação ou na rejeição identitária, de acordo com as circunstâncias do antilusitanismo acirrado por lutas e conflitos armados de caráter nacionalista (RIBEIRO, 1997; ROWLAND, 2000).

Na segunda metade do século XIX, as lutas em torno do processo de abolição e da Proclamação da República vão ganhar espaço em meio aos imigrantes portugueses e suas instituições. Uma parte significativa dos comerciantes lusos e profissionais liberais era associada às lojas maçônicas existentes no Pará desde o ano de 1831, com a loja Tolerância, ou, mesmo, aquelas fundadas a partir da década de 1850, como Harmonia e Fraternidade, Renascença, Grande Oriente, Fênix 27. Essas lojas vão apoiar diretamente a abolição de escravos, financiando cartas de alforria, e, ainda, participando ativamente das discussões em torno do republicanismo. Essas ideias ganhavam as tintas dos jornais apoiados e/ou escritos por portugueses, como $A$ Voz do Caixeiro e O Protesto, este último pertencente ao Centro Republicano Português no Pará (COELHO, 2005, p. 367-368). A maçonaria, assim como os jornais, foram componentes expressivos na formação da sociabilidade portuguesa no Estado, arregimentando pequenos e grandes comerciantes, além de profissionais liberais do mundo urbano; divulgando o positivismo lusitano, republicano e científico; contrapondo-se aos aristocratas, proprietários de terra e escravos, parte deles também portugueses; ampliando as fissuras na então colônia portuguesa do Pará.

\section{Redes migratórias e associações}

\footnotetext{
38 Instituto Arquivo Nacionais/Torre do Tombo (Lisboa), Ministério dos Negócios Estrangeiros, cx. 306, m0031.

39 Instituto Arquivo Nacionais/Torre do Tombo (Lisboa), Ministério dos Negócios Estrangeiros, cx. 306, m0044.

40 Instituto Arquivo Nacionais/Torre do Tombo (Lisboa), Ministério dos Negócios Estrangeiros, cx. $306, \mathrm{~m} 0045$.

41 Instituto Arquivo Nacionais/Torre do Tombo (Lisboa), Ministério dos Negócios Estrangeiros, cx. 306, m0045.

42 Instituto Arquivo Nacionais/Torre do Tombo (Lisboa), Ministério dos Negócios Estrangeiros, cx. $306, \mathrm{~m} 0045$.
} 
É importante realçar que os deslocamentos migratórios não são apenas determinados por questões políticas e econômicas do país de origem ou de destino, mas, também, fruto de escolhas e projetos individuais e/ou familiares. As vantagens abertas pela economia da borracha, que tornavam Belém uma cidade atraente para a migração, aliada à crise econômica e política pela qual passava Portugal ${ }^{43}$, podem nos ajudar a entender a imigração para o Brasil. Entretanto, dentre tantas cidades no país com economia em expansão à época, por que migrar para o Pará? Parte dessa resposta pode ser encontrada nas redes sociais formadas por esses indivíduos. Muitas vezes, um conterrâneo que havia migrado para o Estado era a ponte que acionava os contatos e as informações minimamente necessárias para a viabilidade das escolhas.

Já salientamos que a vinda de Francisco Gaudêncio da Costa para o Pará, na primeira metade do século XIX, ocorreu em função da presença da família na cidade vizinha, no Maranhão. Sua fixação no Estado significava a possibilidade de expansão dos negócios familiares e o apoio em terras novas.

Outro claro exemplo dessas pontes e influências pode ser encontrado em meio aos vários comerciantes advindos da freguesia de Santo Tirso, localizada ao norte de Portugal. Nomes como José Antônio Martins e Constantino Martins, que viveram no Pará na segunda metade do século XIX, onde montaram firmas e se beneficiaram com o comércio da borracha. Antes deles, o conterrâneo de Santo Tirso, Manoel José Ribeiro, o Conde de São Bento, havia feito fortuna no Pará. Manoel era filho de caseiros, atividade doméstica que implicava em administrar ou arrendar fazenda ou casa de outrem (FARIA, 1859, p. 700). Enriqueceu após migrar para Belém, nas primeiras décadas do século XIX, tornando-se um dos homens mais ricos de Santo Tirso e um grande benemérito da freguesia. Trajetórias como as do conde de São Bento acionavam esperanças, acalentavam a expectativa de fortuna, além de favorecer a (re)articulação de redes sociais já montadas por outros conterrâneos.

Ainda pensando nas redes formadas por pessoas de uma mesma localidade, destacamos que os já citados José Antônio Martins e Constantino Martins eram irmãos. No início do século XX, eles retornaram para Santo Tirso, mas seus filhos e sobrinhos migraram para o Pará e foram trabalhar na firma de portugueses conhecidos de seus familiares. Uma geração de homens solteiros migrou de Santo Tirso para o Pará, ao longo de todo o século $\mathrm{XIX}$ e início do XX, atuando no comércio, adquirindo bens e casando-se, como foi o caso de Armando, sobrinho do Barão de Monte Córdova, que, no ano de 1911, estabeleceu matrimônio com Maria Luísa Veloso, filha de imigrante português (CANCELA, 2016).

Práticas como essas acionavam contatos, facilitavam o deslocamento e a fixação em um novo lugar, minimizando as incertezas do cotidiano, criando e rearticulando vínculos e redes familiares, de conterrâneidade e de amizade.

Uma vez na cidade, esses indivíduos mantinham suas redes de sociabilidade através de sociedades comerciais e associações, várias delas criadas no século XIX. Em 1854, temos a fundação da Sociedade Portuguesa de Beneficência (PACHECO, 1920, p. 5). Já no ano de 1867, distribuíram-se listas na "colônia" para a criação do que viria a ser o Gabinete Portuguêz de Leitura, conhecido como Grêmio Literário Português, que tinha como objetivo inicial "instruir na língua nacional e nas estrangeiras, fundando-se também uma biblioteca." (PACHECO, 1920, p. 17) A essas associações seguiram-se outras, como a Associação Vasco da Gama, criada em 1898, voltada para o socorro mútuo.

Nas diretorias dessas associações, encontramos os nomes de muitos portugueses enriquecidos com a borracha. Pessoas como Fortunato Alves de Souza (GUIMARÃES,

\footnotetext{
43 Os motivos dessa emigração são, com frequência, descritos pela historiografia que trata do tema. 0 crescimento populacional de Portugal, a formação de relações capitalistas na agricultura, na pesca e no artesanato, a não absorção da mão de obra pelo mercado e a indústria lusa, o limite de terra das famílias e as dificuldades de herança são alguns dos fatores que contribuíram para a miséria, o desemprego e/ou subemprego naquele país, potencializando a migração. (PEREIRA, 2002, p. 15-24).
} 
2015), o já referido José Antônio Martins (Barão de Monte Córdova), Domingos José Dias (Visconde de São Domingos) e tantos outros (CANCELA, 2016).

É importante destacar que, nesses espaços associativos institucionalizados de convívio, os imigrantes criavam raízes mais duradouras junto à sociedade que lhes serviu de destino. Uma vivência pontilhada por longos anos de interação com a sociedade de destino, sem contudo deixar de acionar marcadores da diferença em relação à sociedade local, em que a participação em associações de caráter nacional é apenas um exemplo. Por outro lado, participar dessas associações na condição de sócio, ou em cargos de diretoria, agregava visibilidade e prestígio aos imigrantes abastados, projetando seus nomes não apenas entre os demais imigrantes, mas também junto à sociedade paraense. Como destaca Marie-Jo Ferreira, a elite portuguesa no Brasil manteve um associativismo forte, centrado em associações beneméritas, culturais e esportistas, com diversos objetivos: "Manifestar o seu poder no interior da colônia portuguesa e, assim, apresentar-se como a representante legítima dos interesses portugueses frente aos governos português e brasileiro, e encontrar na sociedade portuguesa, assim como na brasileira, um certo prestígio social" (FERREIRA, 2007, p. 3).

Desse modo, na festa dos cinquenta anos da Sociedade Beneficente Portuguesa do Pará, estavam presentes o senador paraense Antônio Lemos e o representante da guarda Nacional, major Antônio Marques de Carvalho. ${ }^{44}$ Também nos eventos comemorativos relativos à história de Portugal, como o referido Centenário do Descobrimento do Caminho das Índias, autoridades e políticos se faziam presentes, evidenciando a força política e a visibilidade da colônia portuguesa no Pará. Através dessas associações, os imigrantes acionavam sociabilidades e redes entre conterrâneos, instituições públicas e autoridades paraenses. Projetavam uma imagem de si que reforçava a sua identidade lusa, demarcavam fronteiras e, ao mesmo tempo, dialogavam com a sociedade de destino reforçando os lugares de pertença nesse jogo de diferença, projeção e interação.

\section{Considerações finais}

As diversas práticas dos imigrantes portugueses analisadas, como as redes sociais, a moradia, o trabalho, a organização política e a criação de associações de caráter mutualista, literária e de lazer, apontam para o fato de que Belém deixava de ser apenas um porto de destino, enriquecimento e retorno para a terra natal.

$\mathrm{Na}$ cidade de Belém, eles viveram uma experiência de contrastes. Muitos barões do comércio viviam em prédios assobradados com gradis de ferro, varanda, diversos cômodos e acabamentos; outros tantos portugueses, viviam nos cortiços, vacarias e casas de porta e janela. Alguns deles abriram grandes casas de comércio, mas também botequins e tavernas que vendiam a retalho. Nas ruas da cidade, circulavam, vendendo água, transportando carga, sendo motorista de bond, seringueiros, vendendo leite, trabalhando como pedreiros, moveleiros, operários, caixeiros, amas de leite, criadas e lavadeiras.

Viveram igualmente a experiência de conflitos políticos durante a luta da independência e do movimento cabano, onde o jogo de pertencimento estava marcado por identidades fluídas, observadas em termos como "brasileiro", "brasileiro adotivo", "português". Acompanharam o processo de abolição da escravidão, criando associações abolicionistas, formando os quadros das lojas maçônicas e dos jornais que defendiam o ideal republicano.

A capital paraense passava a se constituir como um local de estadia mais ampla, com cenas protagonizadas por sujeitos que, embora fossem representados e, por vezes, se representassem como pertencentes à colônia portuguesa do Pará, possuíam marcadores sociais distintos. Sujeitos que imprimiram na urbe vivências, representações e memórias múltiplas, pautadas pela construção de uma identidade nacional uniforme reforçada nas festas, nas comemorações e nas associações; mas, também, fissurada por tensões e

\footnotetext{
44 Jornal O Comércio do Porto, 1 nov. 1904, fl. 1.
} 
assimetrias no interior do próprio grupo de imigrantes. Identidade portuguesa que podia ser mobilizada de forma laudatória e comemorativa, ou, mesmo, subsumida frente ao antilusitanismo que marcou mais acentuadamente as lutas da primeira metade daquela centúria, e, ainda, as posições políticas abolicionistas e republicanas assumidas. No entanto, para além dessa multiplicidade, as trajetórias dos sujeitos se uniam na perspectiva de melhoria da condição social e na experiência dos deslocamentos entre um porto português e um porto paraense, que fez de Belém um dos maiores destinos migratórios lusitanos.

\section{Referências bibliográficas:}

ANDERSON, Benedict. Comunidades imaginadas. São Paulo: Companhia das Letras, 2008.

ALVES, Jorge Fernandes. Os brasileiros: Emigração e retorno no Porto oitocentista. Porto: Gráficas reunidas, 1994.

CAETANO, Marcelo A codificação administrativa em Portugal (Um século de experiência, 1836-1935). Lisboa: Tipografia da Empresa Nacional de Publicidade, 1935.

CANCELA, Cristina Donza. Casamento e família em Belém. 1870-1920. Belém: Açaí, 2011.

Redes, gerações e negócios: uma família de imigrantes portugueses na Amazônia. Petrópolis. Antíteses, Londrinav. 9, n. 17. p. 136-156, jan./jul, 2016.

; COSME, João Santos Ramalho. Entre fluxos, fontes e trajetórias: Imigração portuguesa para uma capital da Amazônia (1850-1920). Estudos Ibero-Americanos, Porto Alegre, v. 42, n. 1, p. 232-254, jan./abr. 2016.

COELHO, Geraldo Mártires. O violino de Ingres: Leituras de História Cultural. Belém: Pakatatu, 2005.

COSME, João Santos Ramalho. Quadros da emigração portuguesa para o Pará (Brasil): 1886-1900. População e Sociedade, Porto, n. 24, p. 75-92, dez. 2015.

GUIMARÃES, Luiz Antonio Valente. De chegadas e partidas: migrações portuguesas no Pará (1800-1850). 2015. Tese (Doutorado em História) - Programa de Pós-Graduação em História, Universidade Federal do Pará, Belém, 2015.

FARIA, Eduardo. Novo dicionário da língua portugueza. 4. ed. Rio de Janeiro: Typographia Imperial e Constitucional de J. Villeneuve E. C.,1850. v. 1.

FERREIRA, Marie-Jo. Os portugueses do Brasil, atores das relações luso-brasileiras, fim do século XIX-início do século XX. Rio de Janeiro: Arquivo da Cidade do Rio de Janeiro, 2007. Disponível em:

$<$ http://www0.rio.rj.gov.br/arquivo/pdf/quartas_no_arquivo/2007/palestra_MarieJoFerreira.pdf >. Acesso em: 2 jan. 2019.

LOPES, Siméia de Nazaré. O comércio interno no Pará oitocentista: Atos, sujeitos sociais e controle entre 1840-1855. 2002. Dissertação (Dissertação em História) - Programa de Pós-Graduação em História Social da Amazônia, Universidade Federal do Pará, Belém, 2002.

MENDES, José Saccheta Ramos. Laços de sangue: privilégio e intolerância à imigração portuguesa no Brasil. Porto: CEPESE, 2010.

MONTEIRO, Miguel. Migrante, emigrantes e "brasileiros": territórios, itinerários, trajectórias (1834-1926). Fafe: [s. ed.], 2000. 
O ÁLBUM DA COLÔNIA PORTUGUESA NO BRASIL. Organizado por Teófilo Carinhas e publicado pela oficina "Gráficas do Número" de Carinhas \& Cia Ltda, 1921.

PACHECO, Fran. O Pará e a colônia portugueza. Belém: Typographia da Livraria Gillet, 1920.

PEDREIRA, Jorge M.; MONTEIRO, Nuno. O colapso do Império e a Revolução Liberal, 1808-1834: História Contemporânea de Portugal.1808-2010. Lisboa: Fundación Mapfre; Objectiva, 2013. Vol.1.

PEREIRA, Miriam Halpern. A política portuguesa de emigração (1850-1930). Bauru; Portugal: EDUSC; Instituto Camões, 2002.

RAIOL, Domingos Antonio. Motins políticos ou história dos principais acontecimentos políticos da província do Pará desde o ano de 1821 a 1835. Belém: UFPA, 1970. Vol. I, II e III.

RICCI, Magda. Cabanos, patriotismo e identidades: outras histórias de uma revolução. In: GRINBERG, Keila; SALLES, R. (Eds.) O Brasil imperial. Rio de Janeiro: Civilização Brasileira, 2011. Vol. 2 (1831-1870).

ROWLAND, Robert. Portugueses no Brasil independente: processos e representações. Oceanos, Lisboa, n. 44, out./dez. 2000.

ROWLAND, Robert. A sombra da Corte: representações do povo no Brasil oitocentista. In: SCOTT, Ana Silvia Volpi; FLECK, E. (Eds.). A Corte no Brasil: população e sociedade no Brasil e em Portugal no início do século XIX. São Leopoldo: Oikos; UNISINOS, 2008. p. 1536.

SABINA, Gladys Ribeiro. A liberdade em construção: identidade nacional e conflitos antilusitanos no Primeiro Reinado. 1997. Tese (Doutorado em História) - Instituto de Filosofia e Ciências Humanas, Programa de Pós-Graduação em História, Universidade de Campinas, Campinas, 1997.

SCOTT, Ana Silvia Volpi. Os portugueses. São Paulo: Contexto, 2010.

Aproximando a metrópole da colônia: família, concubinato e ilegitimidade no noroeste português (século XVIII e XIX). In: ENCONTRO DA ASSOCIAÇÃO BRASILEIRA DE ESTUDOS POPULACIONAIS (ABEP), 13., 2002, Ouro Preto. Anais [...]. Ouro Preto, ABEP, 2002.

SERRÃO, Joel. A emigração portuguesa: sondagem histórica. Lisboa: Livros Horizonte, 1974. (Coleção Horizonte, n. 12)

SILVA, António Delgado da. Coleção da legislação portuguesa desde a última compilação das Ordenações. Redigidas pelo Desembargador Antonio Delgado da Silva, Legislação de 1750 a 1762. Lisboa: Typografia Maigrense, 1830.

TAVARES, Andrea Caroliny da Costa. Em busca das patacas: patrimônio de portugueses na economia da borracha (Belém, 1840-1930). 2015. Dissertação (Mestrado em História) Programa de Pós-Graduação em História, Universidade Federal do Pará, Belém, 2015.

TRUZZI, Osvaldo. Italianidade no interior paulista: percursos e descaminhos de identidade étnica (1888-1950). São Paulo: Unesp, 2016. 